$$
\text { CONF-970503-140 }
$$

\title{
Jefferson Lab Personnel Safety Fast Beam Kicker System
}

\author{
K. Mahoney, O. Garza, E. Stitts, H. Areti, M. O'Sullivan \\ Thomas Jefferson National Accelerator Facility, Newport News, Virginia 23606
}

\begin{abstract}
The CEBAF accelerator at Thomas Jefferson National Accelerator Facility (Jefferson Lab) uses a continuous electron beam with up to 800 kilowatts of average beam power. The laboratory beam containment policy requires that in the event of an errant beam striking a beam blocking device, the beam must be shut off by three methods in less than 1 millisecond. One method implemented is to shut off the beam at the gun. Two additional methods have been developed which use fast beam kickers to deflect the injector beam on to a water cooled aperture. The kickers designed and implemented at Jefferson Lab are able to deflect the injector beam in less than 200 microseconds. The kicker system includes self-test and monitoring capabilities that enable the system to be used for personnel safety.
\end{abstract}

\section{Introduction}

The CEBAF accelerator personnel safety system (PSS) is segmented into six geographical areas to allow flexibility in operation and maintenance of the machine. "Critical Devices" were defined which are used to ensure that beam cannot be transported from a segment under beam operations to a segment which may be open for access. Copper beam stoppers were chosen as one of the methods to ensure that beam cannot reach an occupied area. Control of arc transport magnets was another.

The CW nature of the CEBAF beam is such that no single device other than a very high power beam dump can withstand beam indefinitely. A beam current monitor system was incorporated into the personnel safety system to ensure that beam detected at a beam stopper would result in the immediate shutdown of the beam at the source [1].

The beam current monitor system can shut off the beam in less than five-hundred micro seconds using three different methods. The first method is to clamp the electron gun modulation source to a cutoff potential.

The second method chosen was to implement fast beam kickers in the $100 \mathrm{keV}$ injector beam line.

The requirements for the beam kickers included the ability to deflect the injector beam out of the beam transport path and on to a water cooled aperture within 200 micro seconds. The system had to be fail safe and incorporate self test and integrity monitoring as well. Just as importantly, the kicker system must not degrade the quality of the electron beam optics in a very sensitive part of the accelerator.

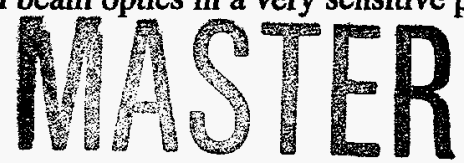

The area chosen for the kicker was in between two emittance defining apertures in the $100 \mathrm{kV}$ section of the CEBAF injector (Figure 1.). Placement at this point relaxed the requirements on the magnetic elements as well as provided a convenient point to dissipate the beam power when deflected out of the beam transport path.

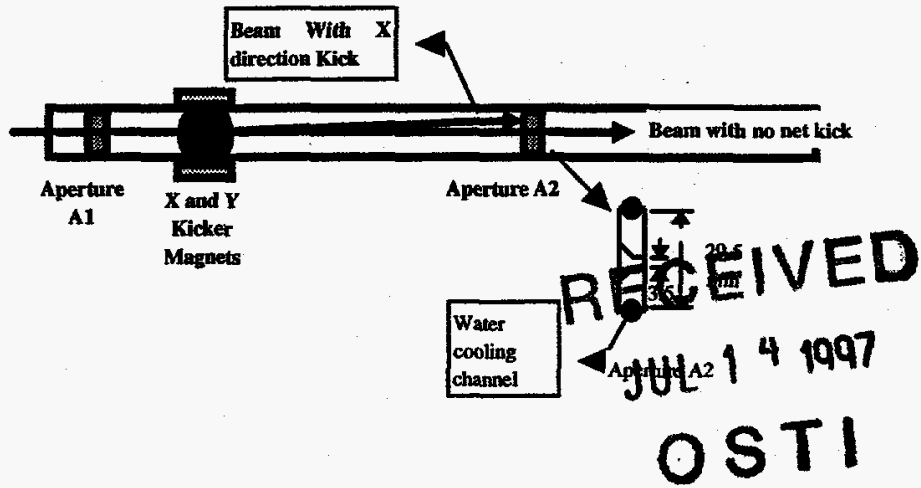

Figure 1. Kicker Beam Line layout

The kicker magnets were placed one half meter up stream of the second aperture. Because the aperture was used to collimate beam, the kicker requirements had to take into account a beam diameter greater than the aperture diameter. Measurements confirmed a beam diameter of approximately $4 \mathrm{~mm}$ at this point.

In order to achieve the required level of redundancy in the kicker function, there are actually 2 kicker magnets, one for the $\mathrm{X}$ plane and one for the $\mathrm{Y}$ plane.

\section{System Description}

The kicker system is designed to have minimal effect on the beam optics when there is no fault, i.e. no kick, and to quickly and efficiently kick the beam out of the beam line when there is a fault. To achieve this, the system was designed such that normally there is equal current in two oppositely biased coils (Figure 2).

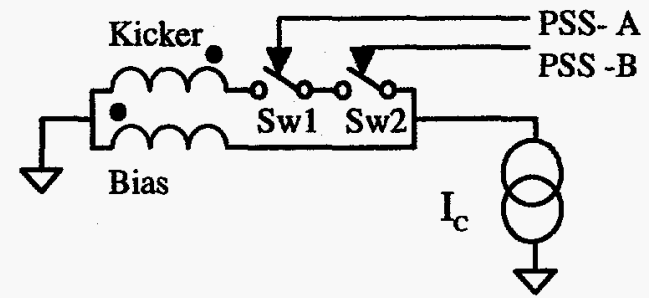

When Sw1 and Sw2 closed $I_{\text {kicker }}=I_{\text {bias }}=I_{d} / 2$

When Sw1 or Sw 2 open $I_{\text {kicker }}=0$; $I_{\text {bles }}=I_{c}$

Figure 2. Kicker Coil Arrangement DISTRIBITTION OF THIS DOCUMENT IS UNLIMITED 
A constant current source ensures that the current is regulated and does not vary more than $0.1 \%$. When there is a fault the current is removed from one of the two coils, leaving a net magnetic field, and thus, a kick. Using the constant current source as the bias element also has another advantage. Normally, one half of the total current is through any one coil. This minimizes the effect of residual fields due to coil mismatch. When one of the coils is open circuited, the current in the other coil is doubled to maintain a constant current. This provides the maximum kick.

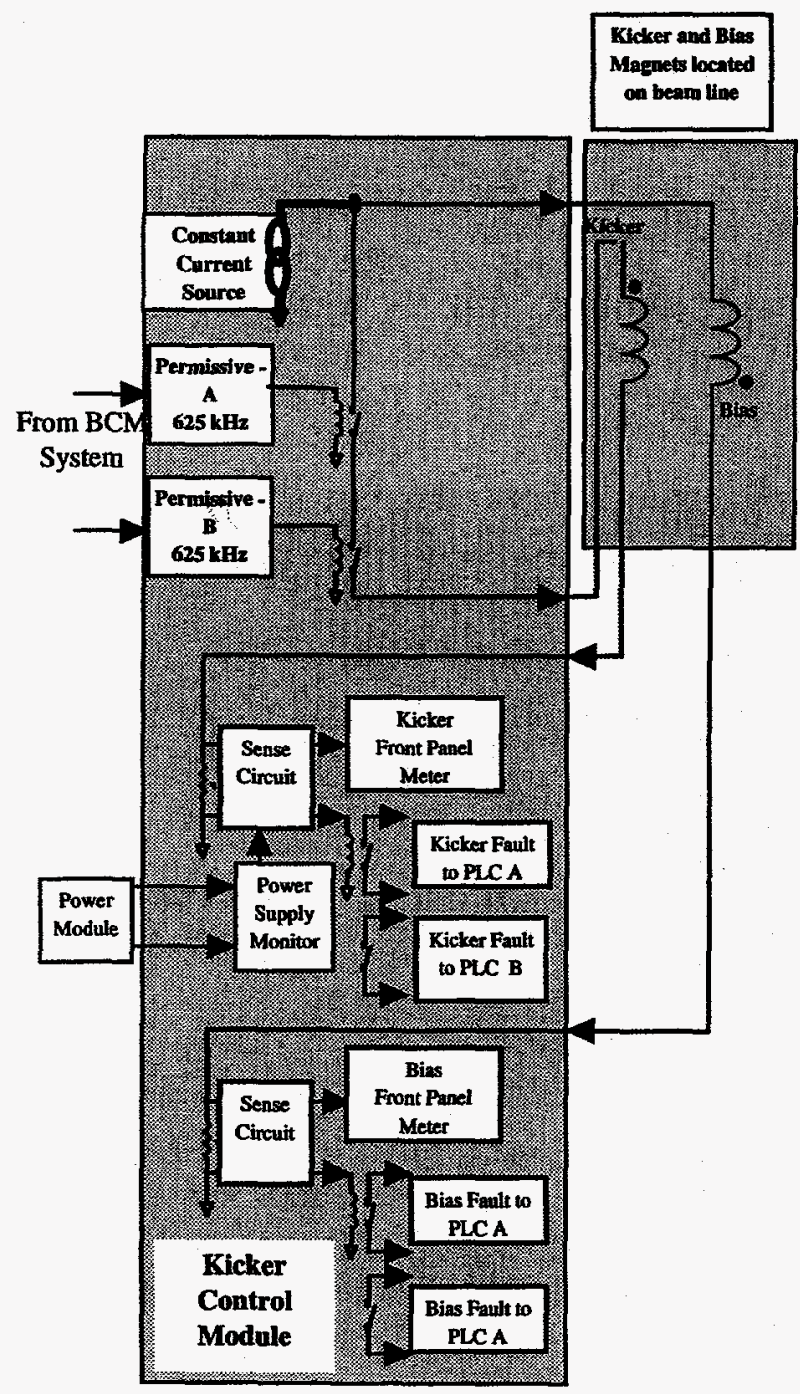

Figure 3. Kicker System Block Diagram

\section{System Hardware}

The kicker system (Figure 3.) is composed of a 3-U electronics card cage located in the upstairs service building and the kicker magnet assembly located on the beam line in the tunnel. The electronics for both the $\mathrm{X}$ and $\mathrm{Y}$ kicker are identical. Each is composed of a power module, a kicker control module and a fiber optic fan-out module.

The power module houses DC power supplies which provide power to the control module. The power can be turned off by a keyswitch located on the back of the chassis.

The control module contains the PSS decoding circuitry, the constant current source, and the fault detection circuitry. The decoding circuitry looks at a $625 \mathrm{kHz}$ squarewave input from each of the redundant beam current monitor systems. Loss of the signal or the signal stuck at one level is interpreted as a fault. Any fault will then open the kicker current line.

The control module uses fast reed relays to switch off the kicker coil current. These relays have a switch off time of less than 100 us. Figure 4 shows the timing of the decoder circuitry. The top trace is the kicker and bias coil current. The bottom trace is one of the two permissive inputs. Once the permissive is off, the kicker coil opens within 160 us. The kicker coil current goes to zero while the constant current source then doubles the current in the bias coil.

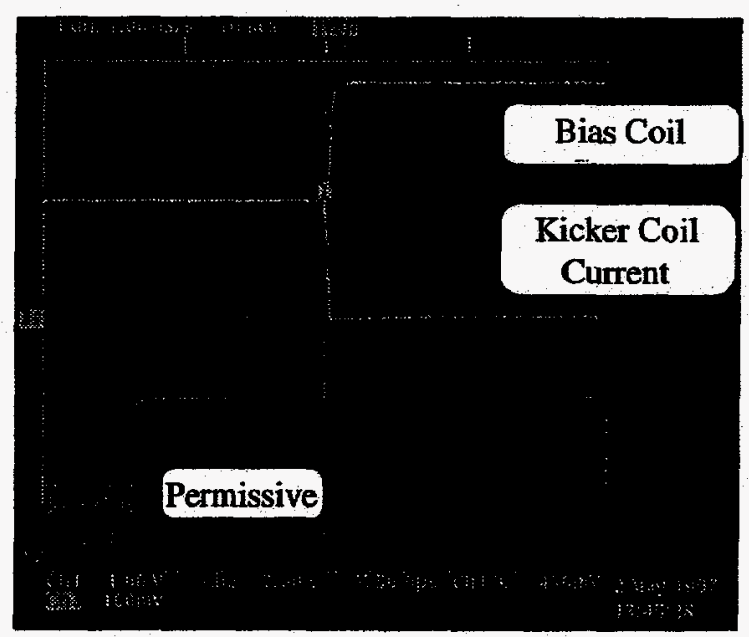

Figure 4. Kicker Timing

Fault detection circuitry on the control module measures current in each coil. A window detector looks for out-oftolerance conditions. The detector is set to detect open circuits or shorted turns on the magnet coils.

An additional set of relays on the control module is connected to the personnel safety system. Any fault on the kicker system will also fault the personnel safety interlock system.

\section{The Kick}

The magnet design is based on a flat solenoid disk electro magnet. The required kick is achieved when one of the two windings is open circuit. Figure 5 shows the magnet assembly. Each of the disks has both kicker and bias coil windings. The magnets are split in two (top-bottom, 
right-left) in order to reduce the current required to achieve the net kick in the center of the beam pipe.

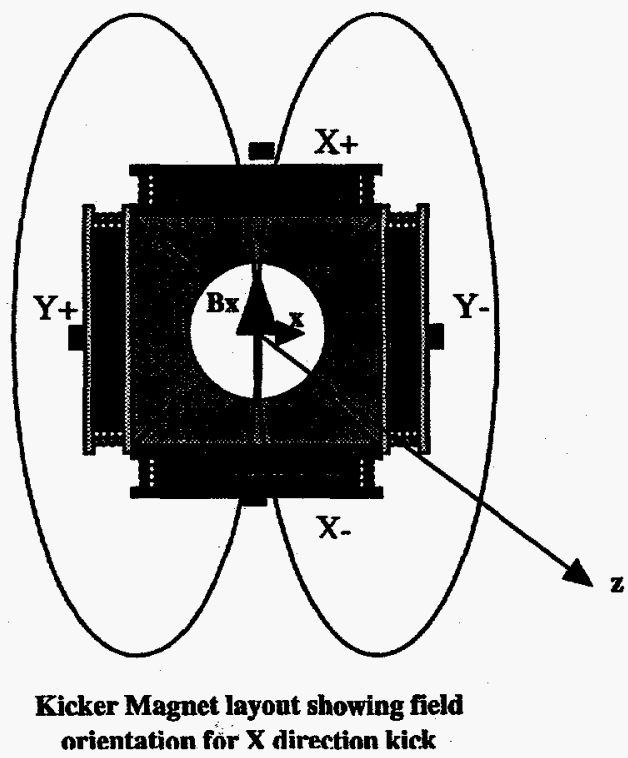

Figure 5.

The magnet assembly was designed for easy mounting and orientation on the beam line. An aluminum block holds both the $\mathrm{X}$ and $\mathrm{Y}$ kicker windings.

The required bending angle to deflect the beam onto thte aperture can be approximated as :

$\Delta \theta=\tan ^{-1}\left(\frac{\Delta x}{L}\right)=\frac{5.87 \times 10^{-4}}{\gamma \beta_{z}} B \mathrm{rad}$

where $\gamma \beta_{z}$ for the $100 \mathrm{kV}$ injector beam is approximately 0.6426 .

The bending power of the kicker magnet was confirmed to be approximately $110 \mathrm{G}-\mathrm{cm} / \mathrm{A}$. To ensure that the beam is kicked completely onto the aperature the current is set to $200 \mathrm{~mA}$. This means that the normally the current in each coil is $100 \mathrm{~mA}$. When there is a fault the current in the bias coil increases to $200 \mathrm{~mA}$ whie the kicker current is switched to zero.

\section{Experience}

The Personnel Safety System Fast Beam Kicker has been in service for over a year. During this time there have been no failures or false trips of any kicker components. More importantly, the kicker current has remained at the original setpoint without any adjustments required. Tests in situ with beam have shown that the kicker has no effect on the beam optics in the "no fault" state. These tests also show that, when tripped, the current is fully deflected onto the aperture, regardless of upstream steering or beam properties.

\section{Summary}

A fail-safe fast beam kicker has been developed at Jefferson Lab which is able to deflect the injector beam onto a water cooled aperture. Deflection time has been measured at much less than the required 200 us. The kicker has no effect on the injector beam properties when there is not a fault condition. Fault monitoring circuitry ensure that no undetected failure modes exist during operation.

\section{ACKNOWLEDGEMENTS}

This work was supported by the U.S. DOE under contract number DE-AC05-84ER40150.

\section{REFERENCES}

[1] R. Ursic et al, "CEBAF Beam Loss Accounting", Proceedings of the 1995 Particle Accelerator Conference, Volume 4.

[2] From Geoffrey Krafft, CEBAF Operator Training material. 


\section{DISCLAIMER}

This report was prepared as an account of work sponsored by an agency of the United States Government. Neither the United States Government nor any agency thereof, nor any of their employees, makes any warranty, express or implied, or assumes any legal liability or responsibility for the accuracy, completeness, or usefulness of any information, apparatus, product, or process disclosed, or represents that its use would not infringe privately owned rights. Reference herein to any specific commercial product, process, or service by trade name, trademark, manufacturer, or otherwise does not necessarily constitute or imply its endorsement, recommendation, or favoring by the United States Government or any agency thereof. The views and opinions of authors expressed herein do not necessarily state or reflect those of the United States Government or any agency thereof. 


\section{DISCLAMMER}

Portions of this document may be illegible in electronic image products. Images are produced from the best available original document. 